Research Paper

\title{
Unilateral Axilla-Bilateral Areola Approach for Thyroidectomy by da Vinci Robot: 500 Cases Treated by the Same Surgeon
}

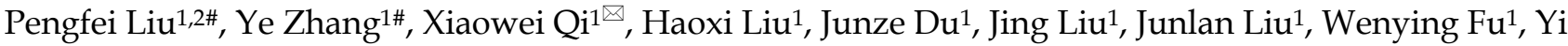 \\ Zhang1, Jun Jiang' ${ }^{1}$ Linjun Fan ${ }^{1 凶}$ \\ 1. Department of Breast and Thyroid Surgery, Southwest Hospital, Third Military Medical University, Chongqing, China \\ 2. Department of Breast Surgery, First Affiliated Hospital, Hunan Traditional Chinese Medical College, Hunan Provence, China \\ \#Contributed equally \\ $\triangle$ Corresponding authors: Linjun Fan, flj212@126.com; Xiaowei Qi, qxw9908@foxmail.com \\ (c) Ivyspring International Publisher. This is an open access article distributed under the terms of the Creative Commons Attribution (CC BY-NC) license \\ (https://creativecommons.org/licenses/by-nc/4.0/). See http://ivyspring.com/terms for full terms and conditions.
}

Received: 2018.11.13; Accepted: 2019.05.04; Published: 2019.06.09

\begin{abstract}
Objective: To investigate the efficacy and safety of da Vinci robot-assisted thyroidectomy via an unilateral axilla-bilateral areola (UABA) approach.

Methods: The clinical data of 500 patients undergoing robotic thyroidectomy via an UABA approach from July 2014 to April 2018 were retrospectively analyzed. All 500 patients were operated on by the same surgeon and divided into two groups by the time sequence. The efficacy and complications were compared between the two groups.

Results: Robotic thyroidectomy via an UABA approach was performed successfully in 500 cases, including 196 cases of benign thyroid diseases with a lesion diameter of $3.1 \pm 1.3 \mathrm{~cm}(0.4-8.2 \mathrm{~cm})$ and 304 cases of thyroid cancer with a tumor diameter of $1.2 \pm 0.7 \mathrm{~cm}(0.4-4.4 \mathrm{~cm})$. Surgical procedures included unilateral lobectomy and total thyroidectomy with or without central lymph node dissection. Among the 500 patients, 9 (1.8\%) had transient recurrent laryngeal nerve injury, 1 $(0.2 \%)$ had permanent unilateral recurrent laryngeal nerve injury, $12(2.4 \%)$ had subcutaneous hemorrhage of the trajectory area, and $6(1.2 \%)$ had subcutaneous infection of the trajectory area after surgery. Among 239 thyroid cancer patients undergoing total thyroidectomy, 45 (18.8\%) had transient hypoparathyroidism and $5(2.1 \%)$ had permanent hypoparathyroidism. The incidence of permanent hypoparathyroidism was $1.9 \%(4 / 212)$ among the patients undergoing total thyroidectomy plus unilateral central lymph node dissection, and 3.7\% (1/27) among the patients undergoing total thyroidectomy plus bilateral central lymph node dissection. During the follow-up of median 17 months, all patients were satisfied with postoperative appearance of the neck and no structural recurrence or metastases occurred. There was no significant difference in efficacy between the two groups $(P>0.05)$, while the complication rate in phase 2 was significantly lower than that in phase $1(P<0.05)$ as the surgeon became more proficient in the UABA approach.
\end{abstract}

Conclusion: Robotic thyroidectomy via an UABA approach is simple, safe, and minimally invasive, suitable for radical resection of large benign tumors and early thyroid cancer and central lymph node dissection.

Key words: da Vinci robot; thyroidectomy; unilateral axilla-bilateral areola approach; efficacy

\section{Introduction}

The incidence of thyroid cancer is increasing every year and thyroid cancer has become the fastest growing cause of malignant tumor in the past 10 years. Surgery is the main treatment for thyroid 
cancer. Conventional open thyroid surgery leaves a noticeable scar on the neck that may affect patient quality of life after surgery [1,2]. At the end of the 19th century, Gagner [3] and Huscher [4] first conducted thyroid surgery under an endoscope, with little effect on the postoperative appearance of the neck [5-8]. In 2005, Lobe et al. [9] in the United States reported the first case of da Vinci robot (da Vinci Si system)-assisted endoscopic thyroid surgery. Subsequently, da Vinci robot was increasingly used for the treatment of thyroid diseases. With the advantages of stabilized 3D lens, remote control, and flexible internal joints, robotic surgery is superior to conventional endoscopic surgery $[10,11]$.

Choe et al. [12] developed a bilateral axilla-breast approach (BABA) and applied it in robotic thyroid surgery, which is convenient and favorable for bilateral operation. Based on the BABA approach, we adopted a unilateral axilla-bilateral areola (UABA) approach for da Vinci robotic surgery in 500 cases from July 2014 to April 2018, and achieved good outcome.

\section{Methods}

\section{General data}

Inclusion criteria were as follows: 1) preoperative diagnosis of benign lesions $<6 \mathrm{~cm}$, or larger if a cyst was observed; 2) thyroid papillary carcinoma $\leq 4 \mathrm{~cm}$ diagnosed by fine-needle aspiration biopsy.

Exclusion criteria were as follows: 1) history of radiotherapy on the head and neck or history of thyroid surgery; 2) thyroid cancer with metastasis to adjacent organs, such as recurrent laryngeal nerve, the esophagus, the trachea, large blood vessels in the neck, or definitive lateral lymph node metastasis on the neck; 3) retrosternal struma; 4) benign lesions diagnosed by preoperative examination and intraoperative frozen-section analysis, but confirmed as thyroid cancer by postoperative paraffin-embedded section analysis; 5) lost to follow-up.

\section{Surgical method}

In our study, all 500 patients with thyroid diseases underwent robotic thyroidectomy (RT) via an UABA approach. For patients without definitive preoperative diagnosis, the removed specimens were sent for frozen section analysis. Unilateral lobectomy or bilateral near-total thyroidectomy was performed for benign thyroid diseases, while unilateral lobectomy plus central lymph node dissection or total thyroidectomy plus central lymph node dissection was performed for thyroid cancer.

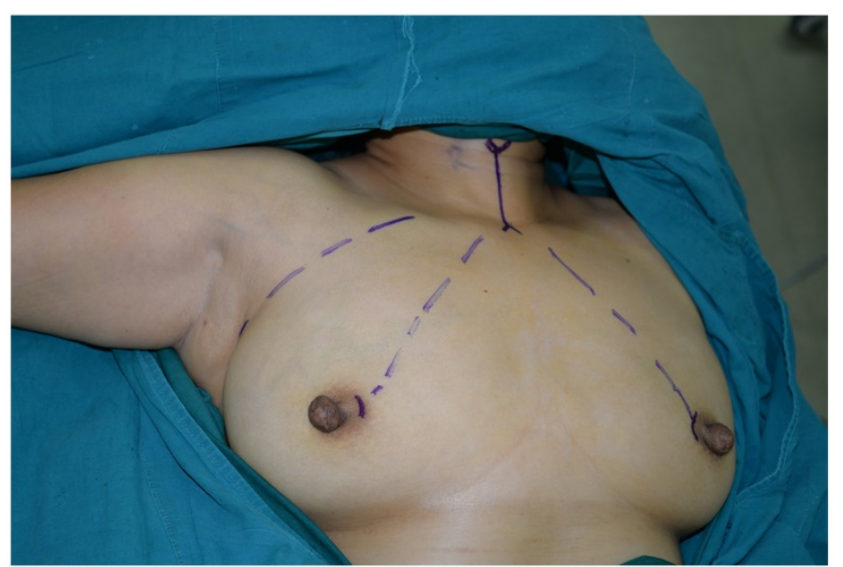

Figure 1. The incision sites were marked on the right axilla and in the medial margin of the bilateral areolae, and the line from each incision site to the superior border of the inner clavicle and right and left sternoclavicular joints, respectively, were used to guide the trajectory of the trocars.

\section{Surgical procedure}

The patient was placed in a supine position, with the shoulders elevated by pads. The head was maintained in a backward and hyperextended position, and the right upper limb was abducted by $90^{\circ}$ to fully expose the axilla, neck, and bilateral areolae. The incision sites were marked on the right axilla and in the medial margin of the bilateral areolae, and the line from each incision site to the superior border of the inner clavicle and right and left sternoclavicular joints, respectively, were used to guide the trajectory of the trocars (Figure 1). In total 200-400 $\mathrm{ml}$ of epinephrine saline (1:200,000, containing $200 \mathrm{mg}$ ropivacaine hydrochloride, 100 $\mathrm{mg}$ /branch, AstraZeneca) was injected into the subcutaneous space along the trajectory to produce swelling. A 1-2 cm skin incision was made according to the preoperative marks. A special trocar was inserted along the pre-marked right axillary route through the subcutaneous space and met two other trocars inserted from the left and right areola to the suprasternal fossa. The robot column was docked along the midline in a cephalad direction. The trocars in the right axilla and left areola were connected to Arms 2 and 1 of the robot, respectively. The trocar in the right areola was connected to the Camera Arm equipped with a 3D lens (Figure 2), and $\mathrm{CO}_{2}$ was insufflated to a pressure of $6 \mathrm{mmHg}$. Under the guidance of images from the lens, the tissue was separated using an elastic separating plier through the trocar in the left areola towards the lens and to the right side in order to establish primary operating space. Fenestrated bipolar forceps (Intuitive Surgical Inc., Sunnyvale, CA, USA) was inserted into the trocar in the right axilla, and a unipolar cautery or harmonic ACE curved shears (Ethicon Endo-Surgery, 


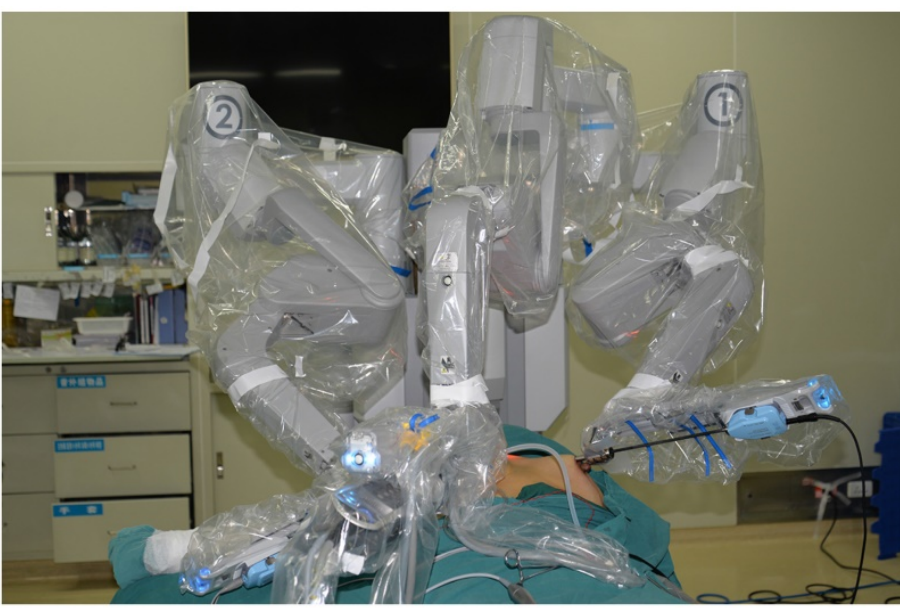

Figure 2. The robot column was docked along the midline in a cephalad direction, with trocars in the right axilla and left areola connected to Arms 2 and 1 of the robot, and a trocar in the right areola connected to Arm 3 equipped with a 3D lens.

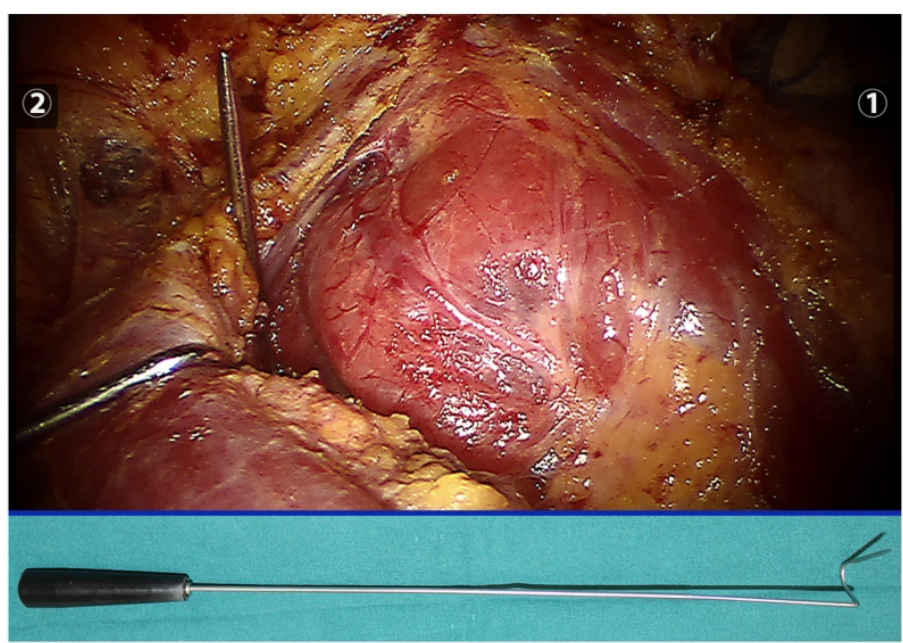

Figure 3. A thyroid retractor was inserted at the intersection between the upper edge of the clavicle and the exterior edge of the sternocleidomastoid muscle to retract the strap muscle laterally and expose the right thyroid (the retractor is indicated below).

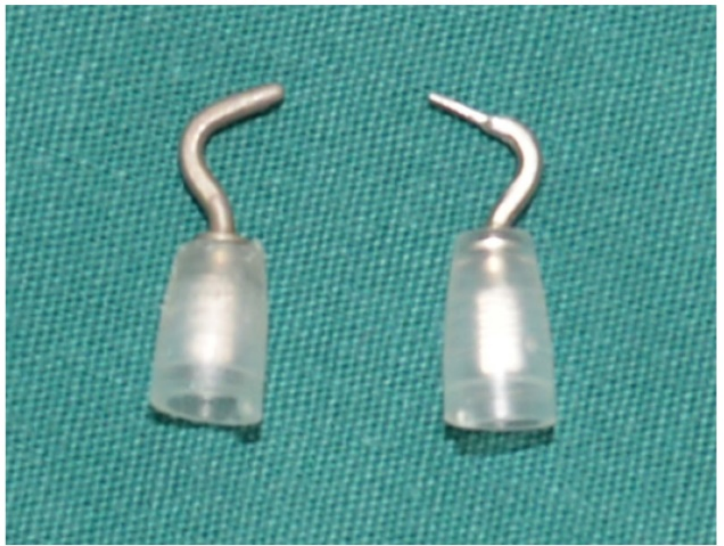

Figure 4. A unipolar cautery dedicated for robotic surgery. Left: original, with tip diameter of $1.2 \mathrm{~mm}$; right: modified, with tip diameter of $0.6 \mathrm{~mm}$.

Cincinnati, OH, USA) were inserted into the trocar in the left areola. Then the surgeon started to dissect the flap from the sternal fossa along the deep surface of the platysma to the upper edge of the thyroid cartilage, bilaterally to the midline of the sternocleidomastoid muscle.

\section{Thyroidectomy}

We cut through the linea alba cervicalis, inserted a thyroid retractor (Kangji Medical Equipment Co., Ltd., Hangzhou, China) at the intersection between the upper edge of the clavicle and the exterior edge of the sternocleidomastoid muscle, and retracted the strap muscle laterally using a thyroid retractor to expose the right thyroid (Figure 3). For patients with a clear diagnosis of thyroid cancer before surgery, $0.1 \mathrm{ml}$ suspension of carbon nanoparticles $(0.5 \mathrm{ml}, 25 \mathrm{mg} /$ branch, Chongqing Laimei Pharmaceutical Co., Ltd., China) was injected into the thyroid parenchyma through the neck skin for tracing central lymph nodes and negative imaging of parathyroid glands. We cut off the thyroid gland isthmus along the midline of the trachea with an ultrasound knife, lifted the inferior thyroid gland using fenestrated bipolar forceps, and then severed inferior thyroid vessels and middle thyroid vein in turn with the ultrasound knife. Attention should be paid to preserve the inferior parathyroid gland and its blood supply, and we called our approach a super-meticulous capsular dissection. During operation, using meticulous capsular dissection technique, a unipolar cautery with a tip of 0.6 $\mathrm{mm}$ (Figure 4) was used to free the thyroid gland along the posterior true thyroid capsule and the trachea to the entry point of the recurrent laryngeal nerve to the larynx. If necessary, part of the true thyroid capsule can be preserved to protect the parathyroid gland and its blood supply. After exposure of the recurrent laryngeal nerve and the superior parathyroid, we cut off the Berry ligament and the pyramidal lobe of the thyroid gland, dissected the thyroid gland upwards to the upper margin along the intrinsic thyroid capsule, preserved the superior parathyroid gland in situ, excised the superior pole and its blood vessels with an ultrasonic knife, and finally completely removed the right thyroid gland. The left thyroid gland can also be removed according to the aforementioned method. During surgery, if the thyroid gland and recurrent laryngeal nerve were closely attached to the larynx, a near-total thyroidectomy was recommended to preserve the recurrent laryngeal nerve and superior parathyroid gland. Small amount of thyroid tissue could be reserved only if the tumor was completely removed. 


\section{Central lymph node dissection}

The fatty lymphatic tissue in front of the trachea was lifted using bipolar grasping forceps, and freed using a cautery from the left edge of the trachea and superior border of the sternum stem to the right. The inferior thyroid vessels and the blood vessels which originated from the trachea and thymus should be closed and cut using an ultrasonic knife or bipolar forceps. The freed tissue in front of the trachea was retracted to the right and dissected deep along the right edge of the trachea. After exposure of the right common carotid artery in the central region, we dissected the carotid sheath, retracted lymphatic tissue in the central region medially to expose the recurrent laryngeal nerve in the tracheoesophageal groove, and removed all lymphatic tissue in the central regions along the recurrent laryngeal nerve from the bottom to the top. The inferior parathyroid

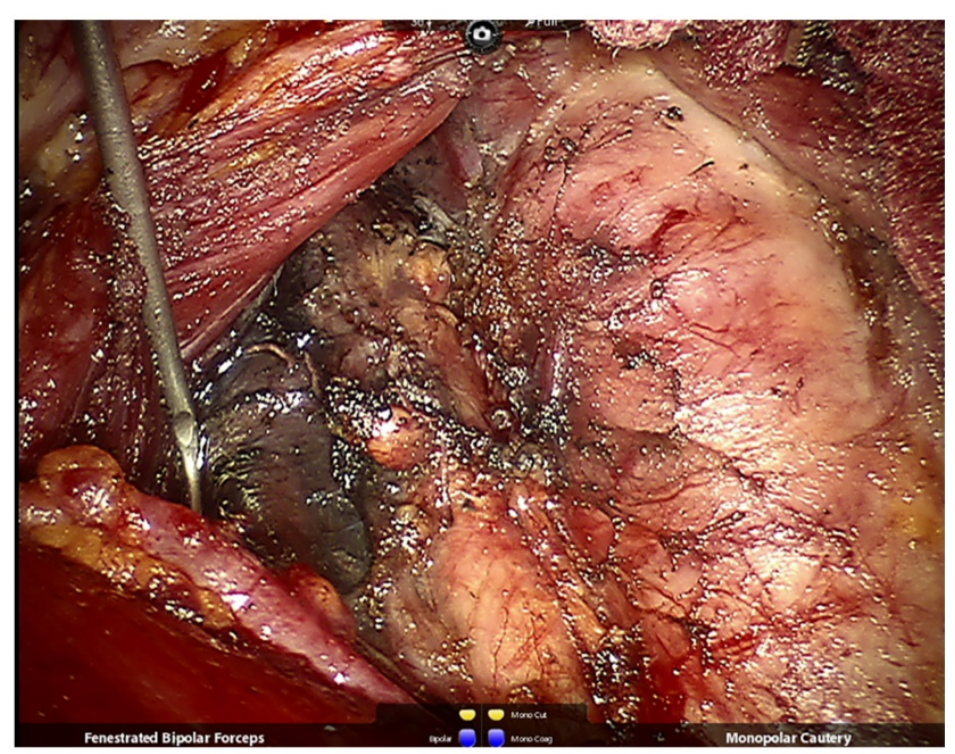

Figure 5. After right thyroidectomy and central lymph node dissection, the right superior and inferior parathyroid glands and recurrent laryngeal nerve are well-preserved.

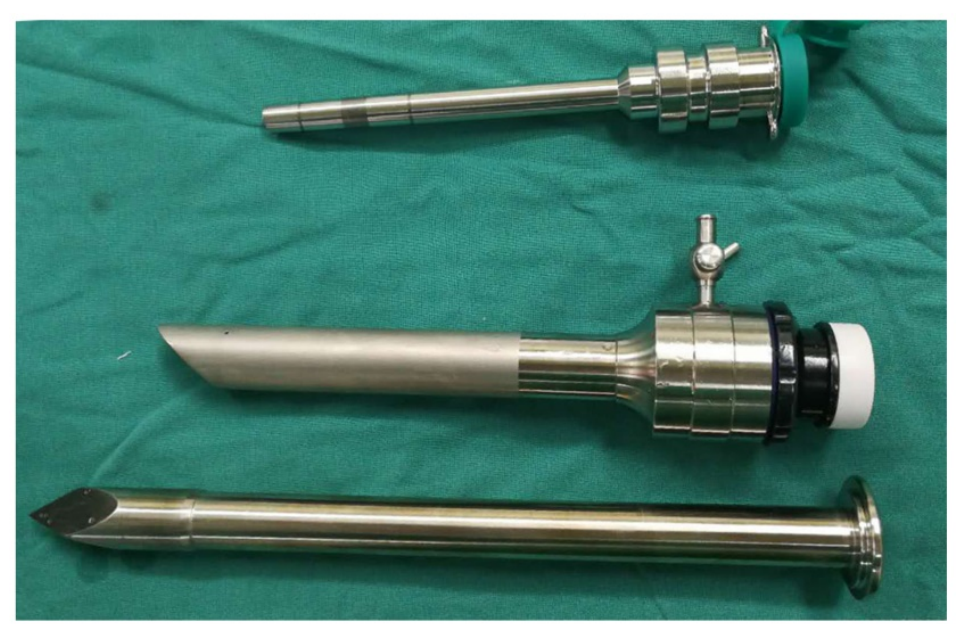

Figure 6. Upper: an $8 \mathrm{~mm}$-diameter trocar for robotic surgery; middle: a $20 \mathrm{~mm}$-diameter trocar for specimen collection; Lower: inner core of a $20 \mathrm{~mm}$-diameter trocar for robotic surgery. gland and its blood supply should be carefully identified and preserved while removing the inferior thyroid gland (Figure 5). The prelaryngeal lymph nodes were removed as well. If the parathyroid glands cannot be preserved or can be preserved in situ but with poor blood supply, ipsilateral sternocleidomastoid muscle transplantation should be performed as follows: one-third of the resected parathyroid gland should be submitted for frozen section biopsy, and the rest cut into pieces and injected into the ipsilateral sternocleidomastoid muscle together with $1 \mathrm{ml}$ of saline.

\section{Specimen collection}

We removed the robotic arm on the left areola, pulled out the trocar, inserted another 20 mm-diameter trocar (Figure 6, Kangji Medical Device Co., Ltd., Hangzhou, China) through this incision, and removed the specimen directly from this trocar. If the minimum diameter of the specimen was more than $2 \mathrm{~cm}$, the specimen can be taken out in several fractions without touching the subcutaneous trajectory. In order to avoid affecting the pathological diagnosis, we cut along the long axis of the specimen and avoid cutting the cancer tissue or suspected cancer tissue. $500 \mathrm{ml}$ of sterilized distilled water was used to rinse the field and the linea alba cervicalis was interruptedly sutured using 4-0 absorbable line. Finally a drainage tube was placed in the right or left thyroid cavity and fixed through the left areola incision.

\section{Postoperative treatment and follow-up}

All patients were given levothyroxine for thyroid function replacement therapy or TSH suppression therapy after surgery. To evaluate postoperative parathyroid function, serum calcium and total intact parathyroid hormone (iPTH) levels were measured before surgery, 3 days after surgery, and 3 months after surgery. Hypoparathyroidism is defined as serum iPTH concentration lower than the reference values $(15-65 \mathrm{pg} / \mathrm{ml})$, regardless of serum calcium concentration [13]. Patients with hoarse voice postoperatively underwent electronic laryngoscopy. Patients with vocal cord paralysis were defined as having recurrent laryngeal nerve injury. If the symptom was relieved within 6 months, recurrent laryngeal nerve injury should be regarded as transient, and if not, permanent. Thyroid function and serum thyroglobulin (TG) under thyroxine inhibition was evaluated postoperatively at 1 , 3 , and 6 months. The patient should be 
examined by cervical ultrasound every 6 months postoperatively. According to the American Thyroid Association (ATA) guidelines, radioactive iodine (RAI) ablation was performed based on the staging of the tumor and risk factors at postoperative 4 to 12 weeks [14]. Patients underwent whole-body scan and diagnostic whole-body scan 2 to 5 days after RAI ablation to determine the uptake of RAI [15]. Six months after operation, patients' satisfaction with neck appearance was evaluated by outpatient review or telephone follow-up.

\section{Statistical analysis}

In order to investigate the effect of surgical proficiency on clinical outcomes and complications, the 500 included cases were divided into two groups based on time sequence. The clinicopathological features, operation time, number of dissected lymph nodes, and complications were compared between the two groups using the chi-square test and $t$-test.

\section{Results}

All 500 patients were successfully operated on using an UABA approach, and none were transferred to an open surgery. There were 400 females and 100 males, with an average age of $42.3 \pm 11.7$ years. The body mass index (BMI) was $23.1 \pm 3.1 \mathrm{~kg} / \mathrm{m}^{2}$. There were 350 patients $(70.0 \%)$ with normal BMI, 24 (4.8\%) with $\mathrm{BMI} \leq 18.5$, and $126(25.2 \%)$ with $\mathrm{BMI} \geq 25$. There were 196 cases of benign thyroid disease, with an average lesion diameter of $3.1 \pm 1.3 \mathrm{~cm}(0.4-8.2 \mathrm{~cm})$, including 116 cases of nodular goiter, 75 thyroid adenoma, and 5 Hashimoto's thyroiditis. Among the 196 patients with benign thyroid disease, 126 underwent unilateral lobectomy and 70 underwent total thyroidectomy. The 304 patients with thyroid cancer were further diagnosed with papillary carcinoma of $1.2 \pm 0.7 \mathrm{~cm}(0.4-4.4 \mathrm{~cm})$ in diameter. Among them, 65 patients underwent unilateral thyroidectomy plus unilateral central lymph node dissection, 212 patients underwent total thyroidectomy plus unilateral central lymph node dissection, 27 patients underwent total thyroidectomy and bilateral central lymph node dissection, and 6 patients underwent autologous transplantation because of poor blood supply to the parathyroid glands (Table 1).

There were no instances of postoperative hypoparathyroidism among the 196 patients with benign thyroid disease. Of 239 thyroid cancer patients undergoing total thyroidectomy, $45(18.8 \%)$ had transient hypoparathyroidism and $5(2.1 \%)$ had permanent hypoparathyroidism. The incidence of hypoparathyroidism after different thyroid surgeries is shown in Table 2. The incidence of permanent hypoparathyroidism was $1.9 \% \quad(4 / 212)$ among patients receiving total thyroidectomy plus unilateral central lymph node dissection, and $3.7 \%$ in patients receiving total thyroidectomy plus bilateral central lymph node dissection $(1 / 27)$.

Table 1. Clinicopathological features of 500 patients receiving robotic thyroidectomy via an UABA approach

\begin{tabular}{|c|c|}
\hline Clinical features & Values \\
\hline Age (years) & $42.3 \pm 11.7$ \\
\hline Gender (male:female) & $100: 400(1: 4)$ \\
\hline BMI (kg/m²) & $23.1 \pm 3.1$ \\
\hline Tumor diameter $(\mathrm{cm})$ & $2.0 \pm 1.4$ \\
\hline \multicolumn{2}{|l|}{ Malignancy } \\
\hline No & $196(39.2 \%)$ \\
\hline Yes & $304(60.8 \%)$ \\
\hline \multicolumn{2}{|l|}{ Tumor staging } \\
\hline T1N0M0 & $138(27.6 \%)$ \\
\hline T1N1M0 & $116(23.2 \%)$ \\
\hline T2N0M0 & $7(1.4 \%)$ \\
\hline T2N1M0 & $17(3.4 \%)$ \\
\hline T3N0M0 & $1(0.2 \%)$ \\
\hline T3N1M0 & $1(0.2 \%)$ \\
\hline T4N0M0 & $22(4.4 \%)$ \\
\hline T4N1M0 & $2(0.4 \%)$ \\
\hline BMI $\left(\mathrm{kg} / \mathrm{m}^{2}\right)$ & $23.13 \pm 3.10$ \\
\hline$\leq 18.5$ & $24(4.8 \%)$ \\
\hline $18.5-25$ & $350(70.0 \%)$ \\
\hline$\geq 25$ & $126(25.2 \%)$ \\
\hline Operation time (min) & $160.3 \pm 50.0$ \\
\hline \multicolumn{2}{|l|}{ Surgery } \\
\hline unilateral lobectomy & $126(25.2 \%)$ \\
\hline total thyroidectomy & $70(14.0 \%)$ \\
\hline $\begin{array}{l}\text { unilateral thyroidectomy plus unilateral central lymph } \\
\text { node dissection }\end{array}$ & $65(13.0 \%)$ \\
\hline $\begin{array}{l}\text { total thyroidectomy plus unilateral central lymph node } \\
\text { dissection }\end{array}$ & $212(42.4 \%)$ \\
\hline $\begin{array}{l}\text { total thyroidectomy and bilateral central lymph node } \\
\text { dissection }\end{array}$ & $27(5.4 \%)$ \\
\hline parathyroid transplantation & $6(1.2 \%)$ \\
\hline Number of dissected central nodes & $5.9 \pm 4.1$ \\
\hline Postoperative hospital stay (days) & $4.9 \pm 2.9$ \\
\hline
\end{tabular}

Table 2. Incidence of hypoparathyroidism after different thyroid surgeries

\begin{tabular}{lll}
\hline Surgery & Transient & Permanent \\
\hline $\begin{array}{l}\text { unilateral lobectomy plus unilateral central } \\
\text { lymph node dissection }\end{array}$ & $3.1 \%(2 / 65)$ & $0(0 / 65)$ \\
$\begin{array}{l}\text { total thyroidectomy plus unilateral central } \\
\text { lymph node dissection }\end{array}$ & $18.4 \%(39 / 212)$ & $1.9 \%(4 / 212)$ \\
$\begin{array}{l}\text { total thyroidectomy plus bilateral central } \\
\text { lymph node dissection }\end{array}$ & $22.2 \%(6 / 27)$ & $3.7 \%(1 / 27)$ \\
\hline
\end{tabular}

Of the 304 patients with thyroid cancer, 118 $(38.8 \%)$ received radioactive iodine treatment within 2 to 3 months after surgery. TG levels under TSH inhibition were determined 6 months after surgery for 239 thyroid cancer patients who underwent total thyroidectomy, indicating TG $<1 \mathrm{ng} / \mathrm{ml}$ in 148 $(61.9 \%)$ patients.

Among all 500 patients, 9 (1.8\%) had significant voice changes and $1(0.2 \%)$ had permanent unilateral recurrent laryngeal nerve injury. Twelve cases $(2.4 \%)$ had subcutaneous hemorrhage of the trajectory area within 1 week after the operation, which was cured by 
irrigation, drainage through the original channel, and local compression. Six cases $(1.2 \%)$ had subcutaneous infection of the trajectory area after the operation, which was relieved after irrigation, drainage, and antibiotics administration. All patients had mild pain or discomfort in the chest wall trajectory area after surgery, but no analgesic was used. During the post-surgical follow-up of 6 to 51 months (median 17 months), all patients developed numbness in the anterior cervical region and chest wall trajectory, which resolved within 1 month and completely recovered within 3 months. All patients were satisfied with postoperative appearance of the neck (Figure 7). No structural recurrence or metastasis was found in any patients during the follow-up period and no death has occurred to date.

All 500 patients were divided into two groups based on operative time sequence. The comparative analysis showed that there was no significant difference in patients' age, gender, tumor size, and clinical stage of thyroid cancer between the two groups (Table 3). However, there were more thyroid cancer patients in phase 2 than in phase 1 (170:134); therefore, more patients in phase 2 underwent unilateral or bilateral central node dissection. The operation time of patients in phase 2 was significantly shorter than that in phase 1 , and the operation time of the total thyroidectomy and unilateral central node dissection was significantly different between the two groups $(\mathrm{P}<0.01$, Table 4$)$. There was no significant difference in number of dissected lymph nodes and the proportion of cases with TG $<1 \mathrm{ng} / \mathrm{ml}$ at postoperative 6 months between the two groups (Table 5). The overall complication rate was significantly lower in phase 2 than in phase $1(\mathrm{P}<$ 0.01 , Table 5). Fewer patients had complications such as hypoparathyroidism, recurrent laryngeal nerve injury, postoperative bleeding, and infection in phase 2 , although there was no statistically significant difference between the two groups.

Table 3. Comparison of clinicopathological features of 500 patients divided into two groups by time sequence

\begin{tabular}{|c|c|c|c|}
\hline Clinicopathological features & $\begin{array}{l}\text { Phase } 1 \\
(n=250)\end{array}$ & $\begin{array}{l}\text { Phase } 2 \\
(n=250)\end{array}$ & $\begin{array}{l}P \\
\text { value }\end{array}$ \\
\hline Gender & & & 0.074 \\
\hline Male & 42 & 58 & \\
\hline Female & 208 & 192 & \\
\hline BMI $\left(\mathrm{kg} / \mathrm{m}^{2}\right)$ & $22.9 \pm 3.1$ & $23.3 \pm 3.1$ & 0.127 \\
\hline \multicolumn{4}{|l|}{ Malignancy } \\
\hline No & 116 & 80 & 0.001 \\
\hline Yes & 134 & 170 & \\
\hline \multicolumn{4}{|l|}{ Tumor size $(\mathrm{cm})$} \\
\hline Benign & $2.96 \pm 1.26$ & $3.20 \pm 1.34$ & 0.209 \\
\hline Malignant & $1.29 \pm 0.84$ & $1.26 \pm 0.84$ & 0.777 \\
\hline Surgery & & & $<0.001$ \\
\hline Unilateral lobectomy & 75 & 52 & \\
\hline Total thyroidectomy & 41 & 28 & \\
\hline $\begin{array}{l}\text { Unilateral lobectomy plus unilateral central } \\
\text { lymph node dissection }\end{array}$ & 17 & 48 & \\
\hline $\begin{array}{l}\text { Total thyroidectomy plus unilateral central } \\
\text { lymph node dissection }\end{array}$ & 108 & 104 & \\
\hline $\begin{array}{l}\text { Total thyroidectomy plus bilateral central } \\
\text { lymph } \\
\text { node dissection }\end{array}$ & 9 & 18 & \\
\hline Tumor staging & & & 0.292 \\
\hline T1N0M0 & 64 & 74 & \\
\hline T1N1M0 & 47 & 69 & \\
\hline T2N0M0 & 3 & 4 & \\
\hline T2N1M0 & 5 & 12 & \\
\hline T3N0M0 & 0 & 1 & \\
\hline T3N1M0 & 0 & 1 & \\
\hline T4N0M0 & 13 & 9 & \\
\hline T4N1M0 & 2 & 0 & \\
\hline
\end{tabular}

Table 4. Comparison of operation time of 500 patients divided into two groups by time sequence

\begin{tabular}{llll}
\hline Surgery & Phase 1 ( min) & Phase 2 (min) & P value \\
\hline Unilateral lobectomy & $144.3 \pm 49.2$ & $130.1 \pm 53.2$ & 0.124 \\
$\begin{array}{l}\text { Total thyroidectomy } \\
\text { Unilateral lobectomy plus }\end{array}$ & $168.1 \pm 50.8$ & $151.0 \pm 49.6$ & 0.170 \\
$\begin{array}{l}\text { unilateral central lymph node } \\
\text { dissection }\end{array}$ & $170.4 \pm 55.4$ & $148.0 \pm 46.4$ & 0.109 \\
$\begin{array}{l}\text { Total thyroidectomy plus } \\
\text { unilateral central lymph node }\end{array}$ & $184.1 \pm 48.2$ & $161.0 \pm 35.6$ & $<0.001$ \\
$\begin{array}{l}\text { dissection } \\
\begin{array}{l}\text { Total thyroidectomy plus bilateral } \\
\text { central lymph node dissection }\end{array}\end{array}$ & $201.0 \pm 60.4$ & $168.2 \pm 46.0$ & 0.129 \\
\hline
\end{tabular}

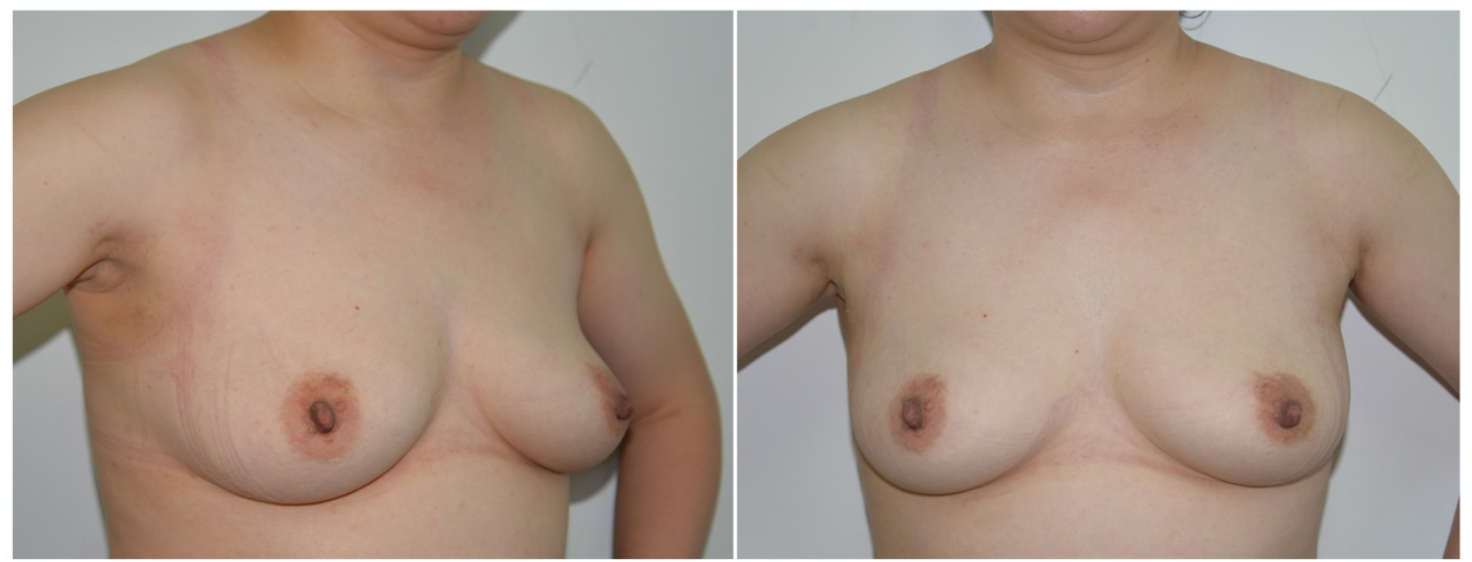

Figure 7. Anteroposterior and lateral views of the neck and breasts six months after robotic thyroidectomy. The surgical scars on the right axilla and left and right areola are occult or insignificant. 
Table 5. Comparison of surgical outcome and complications of 500 patients divided into two groups by time sequence

\begin{tabular}{|c|c|c|c|c|}
\hline Parameters & Phase 1 & Phase 2 & Total $(\%)$ & $P$ value \\
\hline \multicolumn{5}{|l|}{ Number of dissected central nodes } \\
\hline Unilateral & $5.7 \pm 4.6$ & $6.2 \pm 3.9$ & $6.0 \pm 4.3$ & 0.576 \\
\hline Bilateral & $9.4 \pm 4.4$ & $10.3 \pm 4.5$ & $10.0 \pm 4.4$ & 0.630 \\
\hline $\begin{array}{l}\mathrm{TG}<1 \mathrm{ng} / \mathrm{ml} \text { after total } \\
\text { thyroidectomy }\end{array}$ & $45 / 117$ & $52 / 122$ & $\begin{array}{l}97 / 239 \\
(40.6 \%)\end{array}$ & 0.513 \\
\hline Complications & 54 & 31 & $85(17 \%)$ & 0.006 \\
\hline Transient hypoparathyroidism & 26 & 21 & $47(9.4 \%)$ & 0.401 \\
\hline Permanent hypoparathyroidism & 5 & 0 & $5(1 \%)$ & 0.061 \\
\hline $\begin{array}{l}\text { Transient recurrent laryngeal nerve } \\
\text { injury }\end{array}$ & 6 & 3 & $9(1.8 \%)$ & 0.340 \\
\hline $\begin{array}{l}\text { Permanent recurrent laryngeal } \\
\text { nerve } \\
\text { injury }\end{array}$ & 1 & 0 & $1(0.2 \%)$ & 0.317 \\
\hline $\begin{array}{l}\text { Subcutaneous hemorrhage of the } \\
\text { trajectory }\end{array}$ & 5 & 1 & $6(1.2 \%)$ & 0.216 \\
\hline $\begin{array}{l}\text { Subcutaneous infection of the } \\
\text { trajectory }\end{array}$ & 8 & 4 & $12(2.4 \%)$ & 0.242 \\
\hline
\end{tabular}

\section{Discussion}

Currently, robotic thyroidectomy approaches include transaxillary approach (TAA), BABA [12], postauricular approach [16], and transoral approach [17]. The former two are widely used. By a TAA approach, it is convenient to expose and excise ipsilateral thyroid gland and lymph nodes, but difficult to remove contralateral thyroid gland and lymph nodes. The BABA approach is favorable for bilateral operation. Both approaches have a good cosmetic effect, but require a wide range of flap dissection outside of the neck, resulting in increased surgical trauma to the chest wall which can be avoided in open surgery. Some scholars define these approaches as maximally invasive surgeries [13-15] with a higher risk of injury and complications outside the thyroid surgical area [18].

In contrast, the UABA approach used in this study leaves three small incisions, one in the axilla and two in the bilateral areolae. The axillary incision previously located in the anterior axillary line is instead present on the midaxillary line, making it more occult. Trocars are directly inserted into the surgical field, which is less invasive. Compared with the BABA approach, the UABA approach only needs three robotic arms, so it has the advantages of shorter docking time, little interaction between arms and instruments, and better exposure of the surgical field (with the aid of the external retractor). In this study, the average operation time for total thyroidectomy plus unilateral central lymph node dissection was $184.1 \mathrm{~min}$ in phase 1 , similar to the value reported in the literature for conventional surgical approaches, and reached $161 \mathrm{~min}$ in phase 2, significantly shorter than most conventional approaches [19-23]. In this study, no analgesic was needed after the operation, and numbness of the chest wall gradually diminished 1 month after surgery and completely resolved 3 months after surgery. At the same time, the axillary incision on the midaxillary line is almost invisible and only small scars on the areola edge are seen in the front view, so this approach has little influence on the appearance of the neck and the breasts. Therefore, the UABA approach is a minimally invasive, aesthetically acceptable, and easy-to-operate approach for robotic thyroid surgery.

Recurrent laryngeal nerve injury and hypoparathyroidism are common complications after thyroid surgery. Although the high magnification and flexible internal joints of the robotic surgery system facilitate meticulous operation, the incidence of recurrent laryngeal nerve injury or hypoparathyroidism after robotic thyroid surgery reported in the literature is not obviously lower than that in open surgery [24, 25]. The incidence of transient and permanent recurrent laryngeal nerve injury in our study was $1.8 \%$ and $0.2 \%$, respectively, similar to or slightly lower than the values reported in the literature. However, the incidence of transient recurrent laryngeal nerve injury in this study may be underestimated, because only the patients with obvious voice changes after surgery were examined by laryngoscopy. It was reported that the incidence of transient and permanent hypoparathyroidism after robotic thyroid surgery was $14 \%$ to $37 \%$ and 0 to $4.8 \%$ [26-28], 36.1\% and $7.0 \%$ after total thyroidectomy plus unilateral central lymph node dissection, and 51.9\% and $16.2 \%$ after total thyroidectomy and bilateral central lymph node dissection, respectively [29]. In this study, the incidence of transient and permanent hypoparathyroidism was $18.4 \%(39 / 212)$ and $1.9 \%$ $(4 / 212)$ after total thyroidectomy and unilateral central node dissection, $22.2 \%(6 / 27)$ and $3.7 \%(1 / 27)$ after total thyroidectomy and bilateral central node dissection, respectively (lower than most of the results reported in the literature). The lower incidence of hypoparathyroidism in this study may be due to good exposure of the surgical field and meticulous capsule dissection during robotic thyroid surgery. We used an ultra-fine cautery tip for meticulous capsule dissection posterior to the thyroid gland. If the parathyroid gland is closely attached to the thyroid gland or inside the thyroid capsule, the cautery tip can free the parathyroid gland and better preserve part of the true thyroid capsule. Different from meticulous capsule dissection for the gland closely attached to the true capsule, this technique is called super-meticulous capsule dissection because the true capsule is partially excised to preserve the parathyroid gland and its blood supply [30]. Compared with the inferior parathyroid gland, the superior parathyroid gland is easier to preserve because of its relatively stable position, but the blood vessel branches are small and 
delicate, and can be damaged by an ultrasonic knife with no internal joint but a large cutting head during dissection between the parathyroid gland and the thyroid capsule. In this study, we used an ultra-fine cautery tip for super-meticulous capsule dissection under the guidance of the robotic system, which effectively protected the parathyroid gland and its blood supply and thereby greatly reduced the incidence of hypoparathyroidism after thyroid surgery.

In most robotic thyroid surgeries reported in the literature, parameters such as the number of dissected lymph nodes and postoperative non-stimulated-TG were similar to those in open surgery. A meta-analysis showed that the postoperative parameters in robotic thyroid surgery were inferior to those in open surgery. Therefore, the FDA withdrew approval for robotic thyroid surgery in 2011 due to concern for large trauma, risk of complications beyond the thyroid surgery area, and higher medical expenses [31]. Our study shows that in 500 cases of robotic thyroid surgery by the same surgeon, with more surgeries accomplished, the surgeon became more experienced, the operation time was shortened, more lymph nodes were removed, and the postoperative complication rate decreased. These observations suggest that the more experienced and skilled the surgeon, the better the surgical outcome. Although the robotic surgery system is superior to open surgery with regard to meticulous operation, the surgical outcome depends on the experience and proficiency of the surgeon. Moreover, robotic surgery has been applied for only a short term and no guidelines or standards on robotic surgery have yet been established. Therefore, the current studies are not adequate to accurately evaluate the clinical value of robotic thyroid surgery.

In the literature, most robotic thyroid surgeries were performed for thyroid cancer with diameter $<2$ $\mathrm{cm}$, and few were for large benign thyroid tumors. This may be due to the narrow operation space on the neck, making it difficult to dissect and remove a large tumor through a trocar. This study included 196 cases of benign thyroid tumors with an average diameter of $3.1 \mathrm{~cm}$ and a maximum diameter of $8.2 \mathrm{~cm}$. All of them were successfully operated on by the robotic system. Small tumors are taken out through a 2 $\mathrm{cm}$-diameter trocar; if the minimum diameter of the specimen is more than $2 \mathrm{~cm}$, the specimen is removed in several fractions [32]. With the monitoring of the 3D lens, the specimen is taken out through a trocar without touching the wall of the subcutaneous trajectory; otherwise, it may increase the risk of ectopic implantation of thyroid tissue or tumor. In a conventional endoscopic or robotic thyroid surgery, the specimens are first placed in a bag and then removed through a subcutaneously enlarged trajectory. This method has two disadvantages: (1) expanding the subcutaneous trajectory will increase surgical trauma; (2) tiny tissue particles of thyroid or tumor may adhere to the outer wall of the specimen bag which has direct contact with subcutaneous tissue during the removal, increasing the risk of seeding in the trajectory area. Cases of thyroid tissue or tumor seeding after endoscopic thyroid surgery all used a specimen bag [33-36]. In this study, we removed the specimen directly through a trocar, and observed no ectopic implantation of tumor or thyroid tissue during the follow-up.

Different from the BABA approach, the UABA approach only has three trajectories, which not only reduces surgical trauma, but also fully exposes the right axilla after exterior abduction of the right upper extremity; the incision on the midaxillary line is more occult, with better cosmetic effect, so the patient is more satisfied with the postoperative appearance of the neck.

The robot surgery system has the advantages of a 3D field of view magnified greater than 10 times, internal joints with 7 degrees of freedom, remote control and filtering of the operator's shaking, providing a precise operation platform for thyroid surgery. However, due to the lack of tactile feedback from a robotic system, the surgeon adapts to this new surgical mode only after adequate clinical practice. Meanwhile, like any other new technique, practice makes perfect in robotic surgery. In conclusion, the UABA approach is simple, safe, and minimally invasive. This approach is not only suitable for the resection of large benign tumors, but also for radical resection and central lymph node dissection for early stage thyroid cancer, and the safety can be further improved with increasing proficiency of the operator. However, our study is based on the experience of 500 cases of robotic surgery by the same surgeon, so the feasibility of robotic thyroidectomy via an UABA approach should be evaluated by more surgeons from the practice and more randomized controlled trials comparing robotic surgery and open surgery.

\section{Acknowledgments}

This study was supported by grants from Chongqing Municipal Public Health Key Project (Science and Technology Innovation Project for Social Livelihood of Chongqing; No. cstc2015shmszx120072) and Clinical Research Funding of Southwest Hospital (SWH2016JSTSYB-41). 


\section{Competing Interests}

The authors have declared that no competing interest exists.

\section{References}

[1] Choi Y, Lee JH, Kim YH, Lee YS, Chang HS, Park CS, Roh MR. Impact of postthyroidectomy scar on the quality of life of thyroid cancer patients. Ann Dermatol. 2014; 26(6): 693-699.

[2] Arora A, Swords C, Garas G, Chaidas K, Prichard A, Budge J, Davies DC, Tolley N. The perception of scar cosmesis following thyroid and parathyroid surgery: A prospective cohort study. Int J Surg. 2016; 25: 38-43.

[3] Gagner M. Endoscopic subtotal parathyroidectomy in patients with primary hyperparathyroidism. Br J Surg. 1996; 83(6): 875.

[4] Hüscher CS, Chiodini S, Napolitano C, Recher A. Endoscopic right thyroid lobectomy. Surg Endosc. 1997; 11(8): 877.

[5] Shimizu K, Akira S, Jasmi AY, Kitamura Y, Kitagawa W, Akasu H, Tanaka S. Video-assisted neck surgery: endoscopic resection of thyroid tumors with a very minimal neck wound. J Am Coll Surg. 1999; 188(6): 697-703.

[6] Ikeda Y, Takami H, Sasaki Y, Kan S, Niimi M. Endoscopic neck surgery by the axillary approach. J Am Coll Surg. 2000; 191(3): 336-340.

[7] Ohgami M, Ishii S, Arisawa Y, Ohmori T, Noga K, Furukawa T, Kitajima M. Scarless endoscopic thyroidectomy: breast approach for better cosmesis. Surg Laparosc Endosc Percutan Tech. 2000; 10(1): 1-4.

[8] Richmon JD, Kim HY. Transoral robotic thyroidectomy (TORT): procedures and outcomes. Gland Surg. 2017; 6(3): 285-289.

[9] Lobe TE, Wright SK, Irish MS. Novel uses of surgical robotics in head and neck surgery. J Laparoendosc Adv Surg Tech A. 2005; 15(6): 647-652.

[10] Newman JG, Kuppersmith RB, O'Malley BW Jr. Robotics and telesurgery in otolaryngology. Otolaryngol Clin North Am. 2011; 44(6): 1317-31, viii.

[11] Holsinger FC, Chung WY. Robotic thyroidectomy. Otolaryngol Clin North Am. 2014; 47(3): 373-378.

[12] Choe JH, Kim SW, Chung KW, et al. Endoscopic thyroidectomy using a new bilateral axillo-breast approach. World J Surg. 2007; 31(3): 601-606.

[13] Rivere AE, Brooks AJ, Hayek GA, Wang H, Corsetti RL, Fuhrman GM. Parathyroid hormone levels predict posttotal thyroidectomy hypoparathyroidism. Am Surg. 2014 Aug;80(8):817-820.

[14] Haugen BR. 2015 American Thyroid Association Management Guidelines for Adult Patients with Thyroid Nodules and Differentiated Thyroid Cancer: What is new and what has changed? Cancer. 2017; 123(3): 372-381.

[15] Lee S, Lee CR, Lee SC, Park S, Kim HY, Son H, Kang SW, Jeong JJ, Nam KH, Chung WY, Park CS, Cho A. Surgical completeness of robotic thyroidectomy: a prospective comparison with conventional open thyroidectomy in papillary thyroid carcinoma patients. Surg Endosc. 2014; 28(4): 1068-1075.

[16] Byeon HK, Koh YW. The new era of robotic neck surgery: The universal application of the retroauricular approach. J Surg Oncol. 2015; 112(7):707-716.

[17] Clark JH, Kim HY, Richmon JD. Transoral robotic thyroid surgery. Gland Surg. 2015; 4(5): 429-434.

[18] Ruhle BC, Ferguson Bryan A, Grogan RH. Robot-Assisted Endocrine Surgery: Indications and Drawbacks. J Laparoendosc Adv Surg Tech A. 2019; 29(2): 129-135.

[19] Seup Kim B, Kang KH, Park SJ. Robotic modified radical neck dissection by bilateral axillary breast approach for papillary thyroid carcinoma with lateral neck metastasis. Head Neck. 2015; 37: 37-45.

[20] Kim WW, Jung JH, Park HY. A single surgeon's experience and surgical outcomes of 300 robotic thyroid surgeries using a bilateral axillo-breast approach. J Surg Oncol. 2015; 111: 135-140.

[21] Arora A, Garas G, Sharma S. et al. Comparing transaxillary robotic thyroidectomy with conventional surgery in a UK population: A case control study. Int J Surg. 2016;27:110-117.

[22] Kwon H, Yi JW, Song RY, et al. Comparison of bilateral axillo-breast approach robotic thyroidectomy with open thyroidectomy for Graves' disease. World J Surg. 2016; 40: 498-504

[23] Cho JN, Park WS, Min SY, et al Surgical outcomes of robotic thyroidectomy vs. conventional open thyroidectomy for papillary thyroid carcinoma. World J Surg Oncol. 2016; 14: 181

[24] Jackson NR, Yao L, Tufano RP, et al. Safety of robotic thyroidectomy approaches: meta-analysis and systematic review. Head Neck. 2014; 36: 137-143.

[25] Kandil E, Hammad AY, Walvekar RR, et al. Robotic thyroidectomy versus nonrobotic approaches: a meta-analysis examining surgical outcomes. Surg Innov 2016; 23: 317-325.

[26] Liu SY, Kim JS. Bilateral axillo-breast approach robotic thyroidectomy: review of evidences. Gland Surg. 2017; 6(3): 250-257.

[27] Choi JY, Kang KH. Robotic modified radical neck dissection with bilateral axillo-breast approach. Gland Surg. 2017; 6(3): 243-249.

[28] Kim MJ, Nam KH, Lee SG, et al. Yonsei experience of 5000 gasless transaxillary robotic thyroidectomies. World J Surg. 2018; 42(2): 393-401.

[29] Zhu J, Tian W, Xu Z, et al. Expert consensus statement on parathyroid protection in thyroidectomy. Ann Transl Med. 2015; 3(16): 230.

[30] Qi X, Du J,Liu H, Cui X, Li Y, Fu W, Jiang J, Fan L. First report of in-situ preservation of a subcapsular parathyroid gland through super-meticulous capsular dissection during robotic radical thyroidectomy. Surg Oncol. 2019; 28: 9-13

[31] Aidan P, Arora A, Lorincz B,et al. Robotic Thyroid Surgery: Current Perspectives and Future Considerations. ORL J Otorhinolaryngol Relat Spec. 2018; 22: 1-9.

[32] Bärlehner E, Benhidjeb T. Cervical scarless endoscopic thyroidectomy: Axillo-bilateral-breast approach (ABBA). Surg Endosc. 2008; 22(1): 154-157.

[33] Li S, Zhang F, Zhang Y,et al. Implantation at sternocleidomastoid and chest wall after endoscopic thyroid carcinoma surgery. Surg Laparosc Endosc Percutan Tech. 2012; 22(4): e239-e242.

[34] $\mathrm{Xi} C, \mathrm{Xu} X \mathrm{X}$, Hong $\mathrm{T}$, et al. Extrathyroidal implantation of thyroid hyperplastic/neoplastic cells after endoscopic thyroid surgery. Chin Med Sci J. 2014; 29(3): 180-184.

[35] Lee YS, Yun JS, Jeong JJ,et al. Soft tissue implantation of thyroid adenomatous hyperplasia after endoscopic thyroid surgery. Thyroid. 2008; 18(4): 483-484.

[36] Espiard S, Petyt G, Lion G, et al. Ectopic subcutaneous implantation of thyroid tissue after glasless transaxillary robotic thyroidectomy for papillary thyroid Cancer. Thyroid. 2015; 25(12): 1381-1382. 